\title{
Trends in Vietnam's Pork Supply and Structural Features of its Pig Sector
}

\author{
Clem Tisdell*
}

School of Economics, The University of Queensland, Brisbane, 4072, Australia

\begin{abstract}
Pork is the single most important source of animal protein in Vietnam and its availability has a substantial impact on the well-being of the Vietnamese. Since 1996, the local supply and per capita availability of pork in Vietnam have increased substantially. The trends in and sources of this growth in supply are identified by analysing official statistics. Differences in regional supply of pork are also identified, as well as regional variations in pork yields. Vietnam's pork industry relies on many small-scale household producers for the bulk of its pork supply. The structure of the sector is investigated and found to be altering slowly - a slight increase in scale of production units has been occurring. The rate of growth in Vietnam's supply of pork has slowed and production could decline despite the large increases in productivity in this sector since the mid-1990s. The industry is still not internationally competitive. Hence, imports of pork from Canada and the USA occurred in the last few years, and these may increase after 2012 when Vietnam should become World Trade Organization (WTO)-compliant. This concerns the Government of Vietnam because it could threaten the economic sustainability of its pig industry. The Government believes that by adopting policies to increase the scale of production of individual pig-producing units, this will shore up the competitive position of its pig sector. This policy is discussed.
\end{abstract}

Keywords: Agricultural economics, agricultural policy, trends in pork supply, pig industry, pig sector, Vietnam.

\section{INTRODUCTION}

With rising incomes in Vietnam in recent years, the Vietnamese market for pork has expanded, the pig sector has become more market-oriented and the demand for better quality pork has increased. At the same time, new techniques for pig production, including the introduction of imported breeds of pigs (see for example [1-3]) have been adopted and this has added substantially to the supply of pork in Vietnam.

Pork is the single most important source of animal protein in Vietnam and virtually all Vietnamese households consume it. This is underlined by the results of a recent survey of meat consumption patterns in Vietnam funded by the Australian Center for Agricultural Research (ACIAR) and conducted by Vietnam's Center for Agricultural Policy (CAP) and the International Livestock Research Institute (ILRI). These results are outlined for example by Phong Anh Nguyen et al. [4]. While per capita consumption of most meats have risen in Vietnam (for instance, beef) with growing incomes in Vietnam, pork still retains its premier position nationally as the type of meat most consumed. There are, however, some regional variations in its relative importance. For example, in some coastal provinces per capita consumption of fish outstrips that of pork. Nevertheless, given the relative importance of pork in the budget outlay of Vietnamese households, changes in the availability of pork in Vietnam have significant implications for the economic well-being of Vietnamese and are of national policy interest.

*Address correspondence to this author at the School of Economics, St Lucia Campus, The University of Queensland, Brisbane, 4072, Australia; Tel: +617 3365 6570; Fax: +617 33657290 ;

E-mail: c.tisdell@economics.uq.edu.au
This article uses official Vietnamese statistics (mainly those of the General Statistical Office of Vietnam) in order to specify national trends in the primary supply of pork in Vietnam to provide insights into the structure of its pig sector in terms of variations in the number of pigs held by different suppliers and to analyse differences in supply of pork coming from the different regions of Vietnam. Some current policy issues facing the future of Vietnam's pig industry are also discussed. While the available statistics have some limitations, they are adequate for establishing broad trends.

In turn, information is provided in this article on trends in the level of Vietnam's pork production, in the number of its pigs, and changes in pork yields, mainly for the period 19962006. Sources of the increases in Vietnam's domestic supply of pork are identified in terms of the relative contributions of changes in its stock of pigs and their yields. Information is also provided on the relative importance of supply of pork by households compared to its supply by other than households, that is registered farms. The dominant source of supply of pork in Vietnam continues to be from households that keep five pigs or less - that is, very small-scale producers. Variations in the regional supply of pork, in the regional size of pig populations and in regional pork productivity are also examined.

\section{TRENDS IN THE LEVEL OF VIETNAM'S PORK PRODUCTION AND IN ITS PER CAPITA SUPPLIES OF PORK}

Fig. (1) graphs the level of Vietnam's pork production between 1996 and 2006. In this period, Vietnam's production of pork (based on liveweight equivalents) rose by $132 \%$. In other words, it more than doubled. Although the growth rate of the increasing production tended to accelerate be- 
tween 1996 and 2005, in 2006 this growth rate declined (Fig. 1). This may signal the beginning of slower future growth in Vietnam's supply of pork. Further analysis (given below) reveals that the slow down in growth of pork production in Vietnam in 2006 was a result of a decline in the number of pigs slaughtered (Fig. 3) and not due to falling pork yields from slaughtered pigs. In fact yields continued to increase strongly (Fig. 4). The reasons for the decline in the number of pigs slaughtered in Vietnam in 2005 are unclear but one reviewer of this article suggested that the occurrence of a serious disease epidemic has been a contributing factor and that this problem continued into 2007 and beyond.

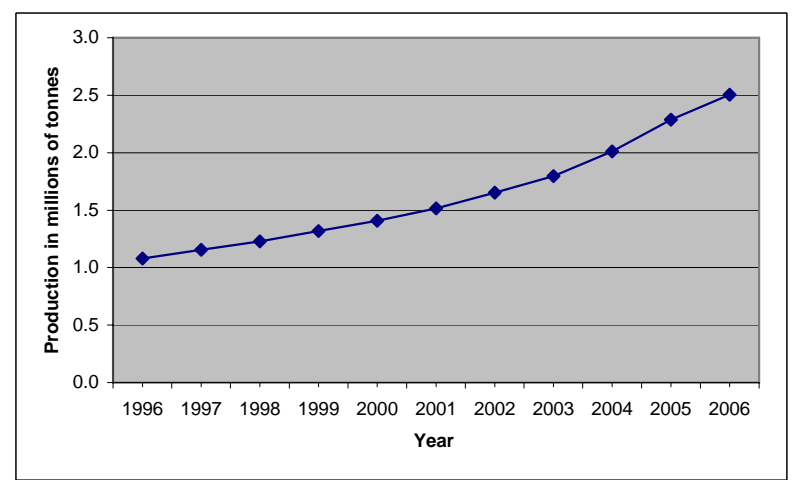

Fig. (1). Vietnam's volume of pork production (liveweight), 19962006. In this period, the volume of Vietnam's pork production rose by $132 \%$ (more than doubled). The growth rate slowed in 2006. (Source: based on [5], Table A1).

The growth in Vietnam's supply of pork outstripped the increase in its population between 1996 and 2006 and consequently, Vietnam's available supply of pork per capita rose. Fig. (2) shows that in this period, Vietnam's per capita supply of pork increased annually but in 2006 its growth rate slowed. Vietnam's supply of pork rose from $14.76 \mathrm{kgs}$ per head of its population in 1996 to $29.77 \mathrm{kgs}$ in 2006. Therefore, it slightly more than doubled. However, a deceleration occurred in the rate of increase in Vietnam's per capita consumption of pork in 2006 because of a decline in the rate of growth of its supply of pork (Fig. 1).

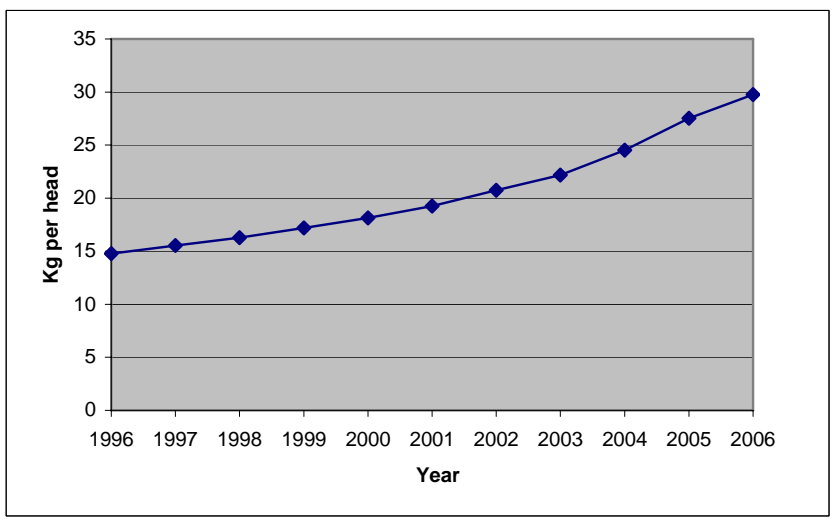

Fig. (2). Per capita production of pork in Vietnam, 1996-2006. Per capita production of pork approximately doubled in this period. A slow down in its growth is evident in 2006. (Source: based on [5], Table A1).
Because, during the period 1996-2006, Vietnam had virtually no imports and no exports of pork, Fig. (2) also shows the level of its per capita consumption of pork (in liveweight equivalents) in this period. However, the situation has now changed and is expected to change further. From 2006 onwards, Vietnam began importation of chilled and frozen pork from Canada and the USA. These nations were able to obtain increased access to the Vietnamese market because Vietnam has joined the World Trade Organization (WTO) and they are able to out-compete Vietnamese producers in supplying some types of pork suitable for processing or for supply to supermarkets. These exports placed some economic pressure on Vietnam's pig industry and resulted in Vietnam raising its tariffs on imported pork in order to provide greater trade protection to its pig industry. This episode signals that Vietnam needs to further increase the economic efficiency of its pig industry if it is to stave off foreign competition in some sectors of this industry. This is needed despite the fact that its yield of pork from its pig stocks has increased by approximately $50 \%$ in the last decade.

Let us consider now the basic factors that have contributed to an increase in the supply of pork in Vietnam in the period 1996-2006. The increase in the volume of pork produced in Vietnam is attributable both to a rise in Vietnam's pig stocks and the growth in the meat yield obtained from these stocks. Let us examine these components.

\section{THE STOCK OF PIGS IN VIETNAM}

The numbers of pigs in Vietnam during the years 1995 to 2006 are graphed in Fig. (3). The number increased in every year between 1995 and 2005 but declined in 2006. The overall increase in pig numbers between 1995 and 2006 was almost $65 \%$. The stocks of pigs in Vietnam increased by more than 10 million in this period. The decline in the number of pigs slaughtered in Vietnam in 2006 was the factor causing the growth in Vietnam's pork production to decelerate (Fig. 1). As Fig. (4) reveals, pork yields per pig continued to rise very strongly in 2006 and to a sufficient extent to more than offset the decline in pork production which would have otherwise come about as a result of the reduction in the number

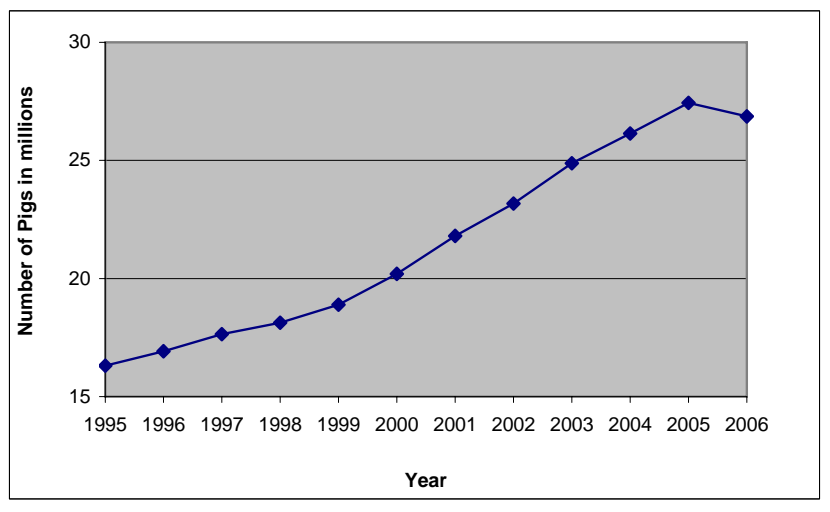

Fig. (3). Number of pigs in millions in Vietnam, 1995-2006. The stock of pigs increased substantially in this period and was a major contributor to increased pork supplies. However, the stock declined in 2006. (Source: based on [5], Table A2). 
of pigs slaughtered. In assessing these trends, it is important to take into account the changing genetic composition of Vietnam's pig stocks.

The genetic composition of Vietnam's stock of pigs has altered significantly in recent decades. There has been a massive infusion of genes from exotic pig breeds into the pig stock of Vietnam and as demonstrated (later) this has important consequences for the level of Vietnam's pork production. As a result of this factor, the population of pigs that are ('pure') local breeds is now very low in Vietnam and mostly are present in areas of the country relatively remote from larger population centres, such as those areas mainly populated by ethnic minorities. An increasing proportion of Vietnam's pig stock consists of exotic breeds crossed with local breeds. Mixed breeds (crosses of local breeds and exotic breeds) constitute more than $90 \%$ of Vietnam's pig stocks according to the results of a recent sample survey conducted by the Center for Agricultural Policy (Vietnam) and the International Livestock Research Institute. The most popular crosses are those between the local Mong Cai breed and exotic breeds. Mong Cai sows tend to have large litters and the offspring of their crosses have superior growth rates compared to local breeds.

\section{THE IMPUTED YIELD (PRODUCTIVITY) OF VIET- NAM'S STOCK OF PIGS}

The yield of pork from Vietnam's stock of pigs rose substantially. It rose from an average of $63.82 \mathrm{kgs}$ per pig in the estimated stock to $93.28 \mathrm{kgs}$ in 2006 , that is by $46 \%$. Average national yields for the period 1996-2006 are graphed in Fig. (4). This graph indicates how the rate of increase in yields has accelerated in recent years. However, yields have not increased in every year since 1996. They declined slightly in 2000 and again in 2001 before displaying a strong upward trend. This pattern could be a reflection of how long it has taken for a new genetic stock of pigs to diffuse as well as the lag in the adoption of new techniques for the husbandry of pigs. In addition, learning-by-doing about new production techniques takes time and those raising pigs would have had to familiarize themselves with new production methods and the best way to husband exotic breeds and their crosses with local breeds.

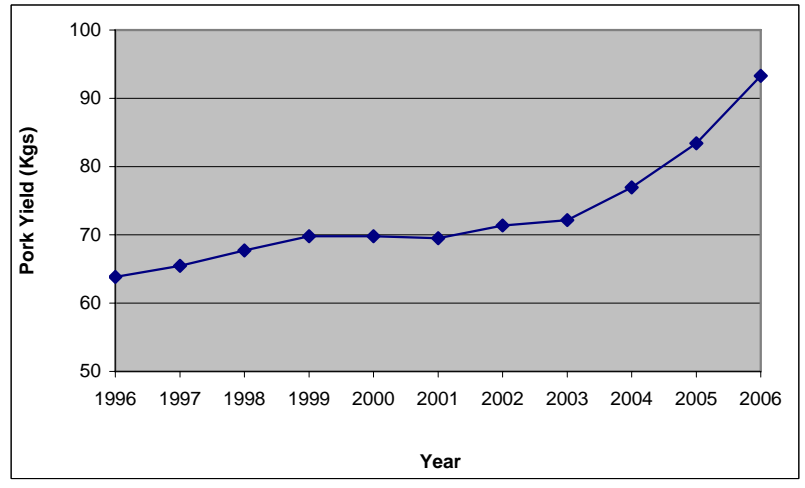

Fig. (4). Pork yields in Vietnam, 1996-2006. Pork yields per pig in the stock rose from $63.82 \mathrm{kgs}$ to $93.28 \mathrm{kgs}$ (that is by $46 \%$ ) in this period and made a significant contribution to increased supplies of pork in Vietnam. Yields have tended to rise at an increasing rate. (Source: based on [5], Table A3).
Rising pork yields indicate increasing intensification of Vietnam's pork sector and suggests rising dependence of this sector on markets. The productivity of exotic pigs and their crosses is sensitive to their feed requirements and their environmental conditions. Most of their food must be obtained commercially. Much of the food is imported [6]. This increases the vulnerability of Vietnam's pig sector to market fluctuations.

Given the measure of yield (productivity) adopted here, (namely the annual volume of pork produced divided by the number of pigs in the stock), factors that may have contributed increased yield (productivity) include:

(i) larger surviving litter sizes;

(ii) faster growth rates of pigs which results in their being marketed at a younger age; and

(iii) fewer boars due to the greater use of artificial insemination.

In turn, each of these factors can be considered further to identify their causes. For example, faster growth rates may be due to genetic improvements, better nutrition, more satisfactory housing of pigs and an increase in their healthiness. It should, however, be noted that increased yields from pig production when measured in the way done here do not necessarily imply that pig production has become more profitable. This would need separate investigation. It requires account to be taken of the extra cost of obtaining the increased productivity and comparing this to the extra revenue obtained.

Although one of the reviewers of this article said that he thought that the main reason for an increase in yield of pork per pig in Vietnam was better nutrition of pigs, it is virtually impossible to isolate the separate influences of the above mentioned factors on increasing yields because all are highly complementary with the introduction of exotic pigs to Vietnam and their crosses with local breeds of pigs. These breeds show greater yield responses to better nutrition, housing and health care than local breeds. Therefore, the introduction of exotic breeds and their crosses has been a prerequisite for rising pork yields in Vietnam. In turn, this development has required better nutrition, housing and health care of pigs as means to raise yields. Modern breeds show much less tolerance to variations in environmental conditions than traditional breeds of livestock [7, 8, Ch. 11].

\section{INCREASED YIELD VERSUS INCREASED PIG STOCKS AS SOURCES OF THE GROWTH IN VIET- NAM'S SUPPLY OF PORK}

For the reasons outlined above which imply nonadditivity of the factors that have contributed to growth in pork yields in Vietnam, the extent of the contribution of the individual growth factors cannot be quantified. However, sources of growth in total pork supplies can be decomposed and quantified. This will enable the determination of the extent to which the expanded supply of pork in Vietnam has been a result of increased pig numbers compared to higher pork yields. Between 1996 and 2006, Vietnam's pork production rose by 1,425,104 tonnes. This increase can be decomposed into three components:

\section{that due to the increase in the number of pigs;}


(B) that due to the rising yield from pigs; and

(C) that due to the multiplicative impact of increased yield and rising pig numbers.

These items are identified in Fig. (5) by the areas marked $\mathrm{A}, \mathrm{B}$ and $\mathrm{C}$ respectively. It is found that increased pig numbers accounted for the largest proportion of the increase $(49.49 \%)$ in pork supply between 1996 and 2006, higher yields contributed $34.98 \%$ of the increase and the combination of rising yield and pig numbers comprised $20.53 \%$ of the growth. Thus overall in this period, both rising pig numbers and yield were important for the growth in the volume of Vietnam's supply of pork, but the increased stock of pigs made the greater contribution.

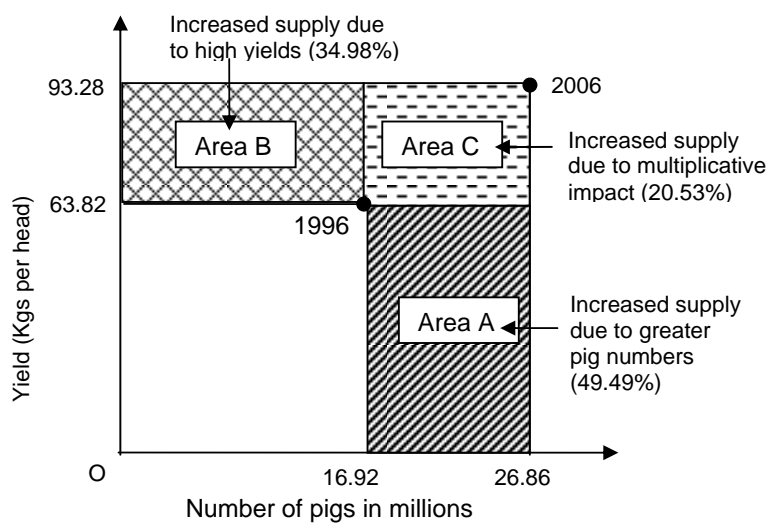

Fig. (5). Decomposition of the increase in volume of pork production in Vietnam in 2006 compared to 1996. The main source of the growth in the volume of pork production was due to increased pig numbers $(49.49 \%)$, increased yields $(34.98 \%)$ and the combined effect of these factors $(20.53 \%)$.

While during the period 1996-2003, rising pig numbers made the largest contribution to the growing supply of pork in Vietnam, from 2004 to 2006 yield became the most important contributor to Vietnam's rising supply of pork. This is illustrated by Fig. (6). From 2003 onwards, intensification of production in the pig industry in Vietnam rose sharply.

\section{THE DISTRIBUTION OF THE SIZE OF PIG HOLD- INGS BY HOUSEHOLDS AND THE RELATIVE IM- PORTANCE OF SMALL-SCALE PRODUCERS IN VIETNAM'S PIG SECTOR}

According to Vietnam's Agro-Census 2001, 7,390,875 households kept pigs and this amounted to $56.57 \%$ of Vietnam's rural households. However, the average number of pigs kept per household was small, namely 2.73 on average per household. Table 1 provides information on the distribution of pigs by the size of the holdings kept by households in 2001. The most frequently held number of pigs was two. Fig. (7) indicates that the relative distribution of pig holdings per household is heavily skewed to the left. Most households had fewer than 6 pigs. The highest number of pigs is accounted for by those households having 3-5 pigs.

In 2001, results from the Agro-Census demonstrated that households accounted for the majority of pigs in Vietnam. From the fact that it was reported that 7,390,875 households held an average of 2.73 pigs each, it follows that households held $20,177,088$ pigs. The total number of pigs present in Vietnam in 2001 was reported to be $21,800,100$. This indicates that $1,623,212$ pigs were not accounted for by households, that is approximately $7.5 \%$ of pigs stocks. These were presumably accounted for by registered farms as opposed to households. Despite shortcomings in these statistics, it seems that around $92.5 \%$ of Vietnam's stock of pigs is accounted for by its household sector.

Data in Table 91 (p.217) of [10] indicate that in 2006 more than half of Vietnamese households (55.72\%) keeping pigs had 2 pigs or less and only $1.75 \%$ had 21 pigs or more. In 2001, the corresponding percentages were $66.8 \%$ and $0.3 \%$ respectively. It can be concluded that the average scale of pig holdings increased between 2001 and 2007, but not dramatically. Vietnam's pork production is still dominated by small-scale producing units. Whereas in 2001, for example, $92.2 \%$ households having pigs had five or fewer pigs in

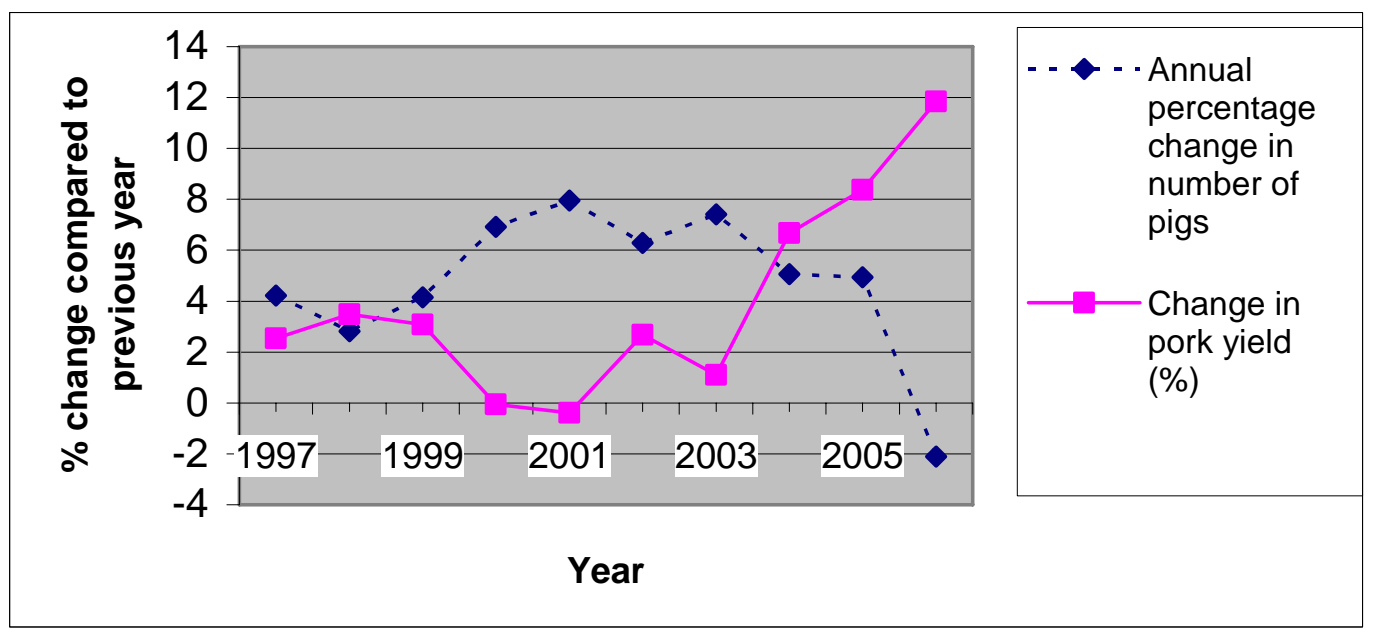

Fig. (6). Annual percentage change in pork yields and number of pigs, Vietnam. 1997- 2006. In earlier years, increases in the number of pigs made the largest contribution to increasing Vietnam's output of pork but in later years increased yields have become the major contributor. (Source: based on [5], Tables A2 \& A3). 
Table 1. Distribution of Pigs Per Pig Household in Vietnam, 2001. Holdings of 5 or Fewer Pigs Dominate the Distribution of Pigs Held by Households. (Source: Adapted from General Statistical Office of Vietnam, 2002[9])

\begin{tabular}{|c|c|c|c|c|c|}
\hline $\begin{array}{c}\text { Scale of Pig Holdings by } \\
\text { Pig Households }\end{array}$ & $\begin{array}{c}\text { Average Approximate } \\
\text { No. of Pigs Per } \\
\text { Household }\end{array}$ & $\begin{array}{c}\text { Number of Households } \\
\text { with Pigs }\end{array}$ & $\begin{array}{c}\text { Total Number of Pigs } \\
\text { for Each Household Size } \\
\text { (Estimated) (a) }\end{array}$ & $\begin{array}{c}\text { \% of Total Pigs } \\
\text { Accounted by Each } \\
\text { Household Size }\end{array}$ & $\begin{array}{c}\% \text { of Households in } \\
\text { Each Category }\end{array}$ \\
\hline 1 & 1 & $2,172,828$ & $2,172,828$ & 10.18 & 29.40 \\
\hline 2 & 2 & $2,764,524$ & $5,529,048$ & 25.91 & 37.40 \\
\hline $3--5$ & 4 & $1,887,408$ & $7,549,632$ & 35.38 & 25.54 \\
\hline $6--10$ & 8 & 446,573 & $3,572,584$ & 16.74 & 6.04 \\
\hline $11--20$ & 16 & 97,024 & $1,552,384$ & 7.28 & 1.31 \\
\hline $21--50$ & 36 & 20,064 & 722,304 & 3.39 & 0.27 \\
\hline 51--99 & 75 & 1,724 & 129,300 & 0.61 & 0.02 \\
\hline \multirow[t]{2}{*}{$100 \&$ above } & 150 & 730 & 109,500 & 0.51 & 0.01 \\
\hline & & $7,390,875$ & $21,337,580$ & 100.00 & 100.00 \\
\hline $\begin{array}{l}\text { Total rural households - } \\
\text { Total pig producing household } \\
\text { Percentage of pig households - } \\
\text { Average No. of pigs per housel }\end{array}$ & $\begin{aligned} & 13,065,756 \\
& 7,390,875 \\
& 56.57 \% \\
\text { sold }- & 2.73\end{aligned}$ & & & & \\
\hline
\end{tabular}

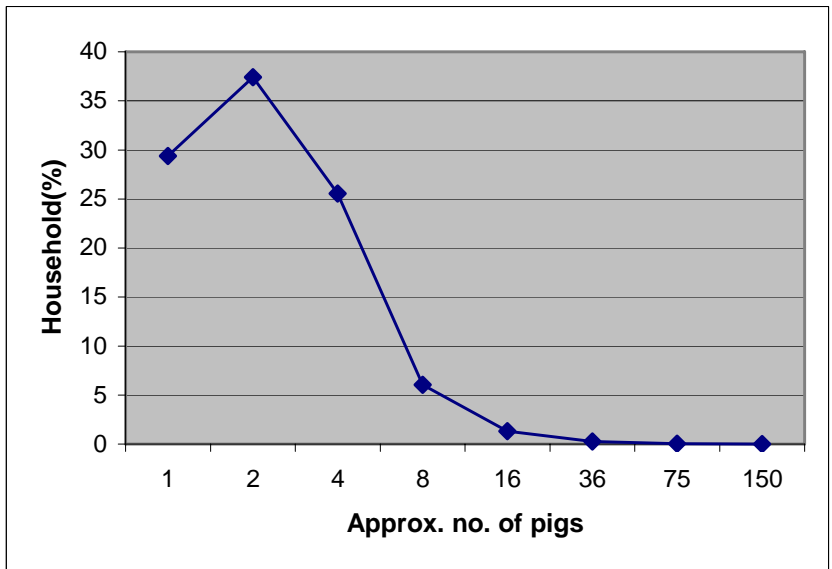

Fig. (7). The distribution of the relative frequency of pig households in Vietnam by approximate number of pigs held in 2001. In 2001 , over $90 \%$ of pigs in Vietnam were held by households. They were the backbone of Vietnam's supply of pork. Most households held few pigs - the average holding was 2.5 pigs per household. (Source: based on Table 1).

2006 this percentage was $83.4 \%$. While this was a reduction, small-scale producers still dominated Vietnam's pig industry. As part of its livestock development policy, the Vietnamese Government plans to adopt measures to increase the size of pig producing units [11]. This will probably favour the development of specialized registered pig farms engaged in commercial industrial-style piggeries. Production units vary from being of a subsistence-type, to being semicommercial, to being completely commercial units. Household pig production is often a sideline activity and a part of farm diversification in Vietnam. Considerable heterogeneity exists in production units although most units have become more involved in market transactions in recent times.

\section{REGISTERED PIG FARMS IN VIETNAM}

Although households are the main suppliers of pigs in Vietnam, there are also separate registered commercial pig farms (piggeries). The general policy of the Vietnamese Government is in favour of expanding production by these commercial enterprises to add to Vietnam's production of pork. Accurate data on the number of registered pig farms in Vietnam and their attributes, such as their sizes, and changes with the passage of time have proven difficult to obtain. It is, however, known that the size of registered farms varies considerably and their average holding of pigs is substantially higher than that of households. Those who have registered farms obtain some concessions and subsidies but are also more likely to be taxed.

Data for 2006 indicate that there were 10,811 registered pig farms in Vietnam (see Table 2). Their regional distribution was very uneven (see Table $\mathbf{2}$ and Fig. 8) with the Red River Delta accounting for more than half of these farms and with the South East Region and the Mekong Delta being next in importance. This suggests that most pig farms tend to be located not too far away from the major cities of Hanoi and Ho Chi Minh City, which are the main markets for their pigs. Farms in the Red River Delta and the North East serve populations concentrated in the Hanoi and Heiphong area whereas those in the South East and Mekong River Delta mainly supply the population concentrated in and around Ho Chi Minh City. These are the main markets and establishing commercial piggeries there is likely to be more profitable than in regions further away. The price of pork tends to be higher in these metropolitan areas than elsewhere in Vietnam and transport costs for marketing are lower. Furthermore, the piggeries there have ready access to pig food much of which is imported and these areas are regional transport nodes. By comparison, there are few registered pig farms in the North 
West because this is well away from major markets and does not have ready access to transported pig food. There are also many ethnic groups in this region engaged in selfsubsistence agriculture.

Table 2. Regional Distribution of Pig Farms in Vietnam in 2006 Three Regions Account for Most of these Farms. (Source: Based on Table 63, pp. 164-165 in [10]).

\begin{tabular}{|c|c|c|}
\hline Region & No. of Pig Farms & Pig Farms (\%) \\
\hline \hline Red River Delta & 5,902 & 54.59 \\
\hline South East & 1,997 & 18.47 \\
\hline Mekong River Delta & 1,179 & 10.91 \\
\hline North East & 790 & 7.31 \\
\hline North Central Coast & 452 & 4.18 \\
\hline Central Highlands & 253 & 2.34 \\
\hline South Central Coast & 210 & 1.94 \\
\hline North West & 28 & 0.26 \\
\hline Total No. of pig farms & $\mathbf{1 0 , 8 1 1}$ & $\mathbf{1 0 0 . 0 0}$ \\
\hline
\end{tabular}

\section{THE REGIONAL DISTRIBUTION OF PIGS AND PORK PRODUCTION IN VIETNAM}

Considerable variation occurs in pig stocks held in the different regions of Vietnam. In 2006, the regions accounting for the largest number of pigs were in declining order: the Red River Delta, the North East Region, The Mekong River Delta and the North Central Coast (see Appendix Table A1). While this ordering is similar when the volume of pork production by regions is considered, the percentage shares alter and the South East moves up the scale (see Appendix Table A2). Nevertheless, there is a high positive association between the number of pigs in each region and the volume of pork supplied in each as can be seen from Appendix Fig. (A1). Observe that there were some changes in the boundaries of regions between 1995 and 2006. My data were not adjusted for regional boundary changes, but this adjustment does not make a significant difference to the findings. Achilles Costales of the FAO reworked the data (see [5] Appendix II) to take account of regional boundary changes and found that the results remained substantially the same as reported here.

Table 3 lists the provinces of Vietnam making up the various statistical regions of Vietnam in 2006 as used by the General Statistical Office of Vietnam [10] to report the results of Vietnam's rural, agricultural and fishery census completed in 2006. The rough location of these regions are shown in Fig. (9) by numbers on a map of Vietnam. Note that the number of provinces constituting these regions and the size of the regions vary considerably. For example, the North East Region contains nine provinces whereas the North West Region contains only three and the former region is much larger than the latter. There can be considerable geographical heterogeneity within regions. For instance, the North East Region stretches from northeast of Hanoi up to China's border and then to the west of Hanoi. It, therefore, includes Bac Giang (which is close to Hanoi) and Ha Giang which is located in the west and is located far away from Hanoi. The nature of pig production in these two provinces can be expected to be quite different even though for official statistical purposes they are included in the same region. Given such geographical heterogeneity, locational diversity of pig production systems and pork yields can be expected to be even greater than reported here, for example in Fig. (12). Nevertheless, even when geographical diversity within regions is ignored, the analysis of the statistical data for Vietnam reported here shows substantial geographical variation in the importance of its pig industry and in its economic performance. This is not surprising given that Vietnam shows a high degree of physical and cultural diversity.

Figs. (10 and 11) graph the distribution of the pig population and the volume of pork supply by the regions of

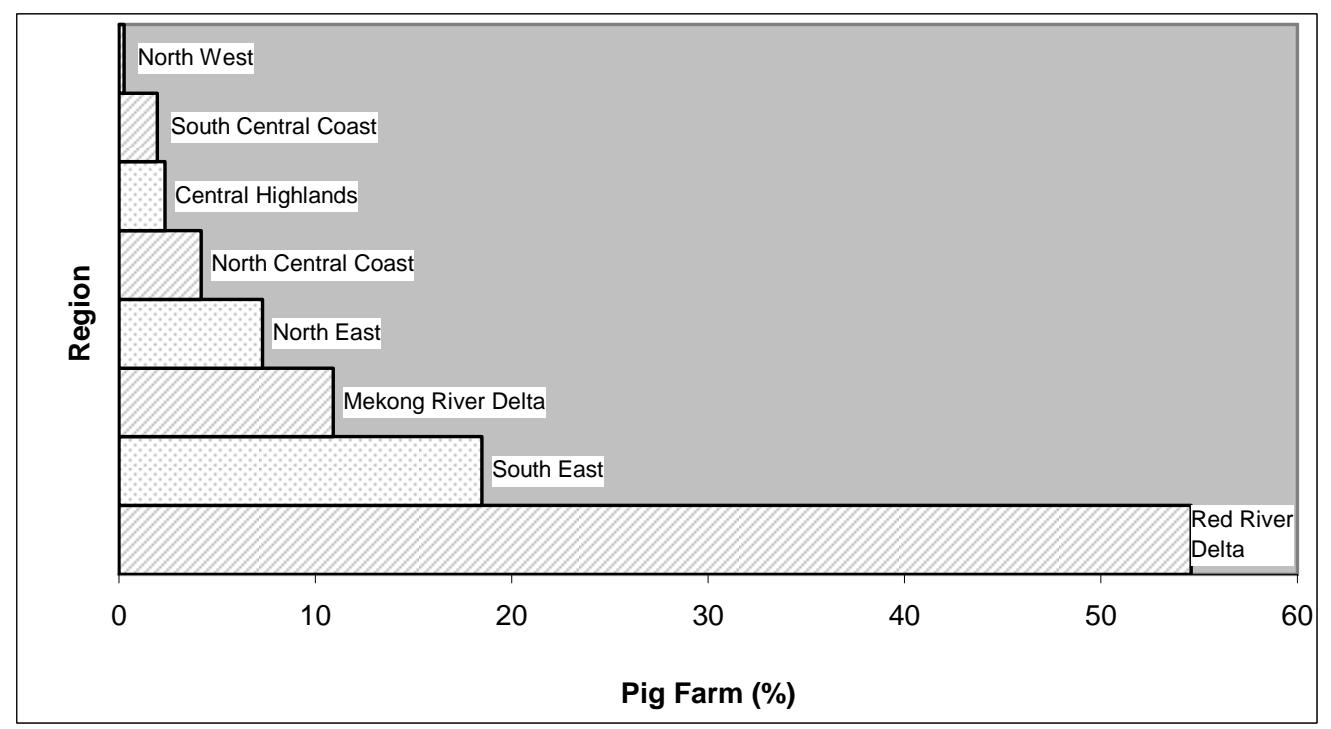

Fig. (8). Regional distribution of pig farms in Vietnam in 2006. Pig farms are not yet the major suppliers of pork in Vietnam. Their regional distribution is uneven. They have a concentration in the regions containing or near Hanoi and Ho Chi Minh City. 
Table 3. A List of the Eight Statistical Regions of Vietnam and their Provinces Used in Reporting Results of the 2006 Rural Agricultural and Fishery Census 2006 by the General Statistical Office [10], Vietnam

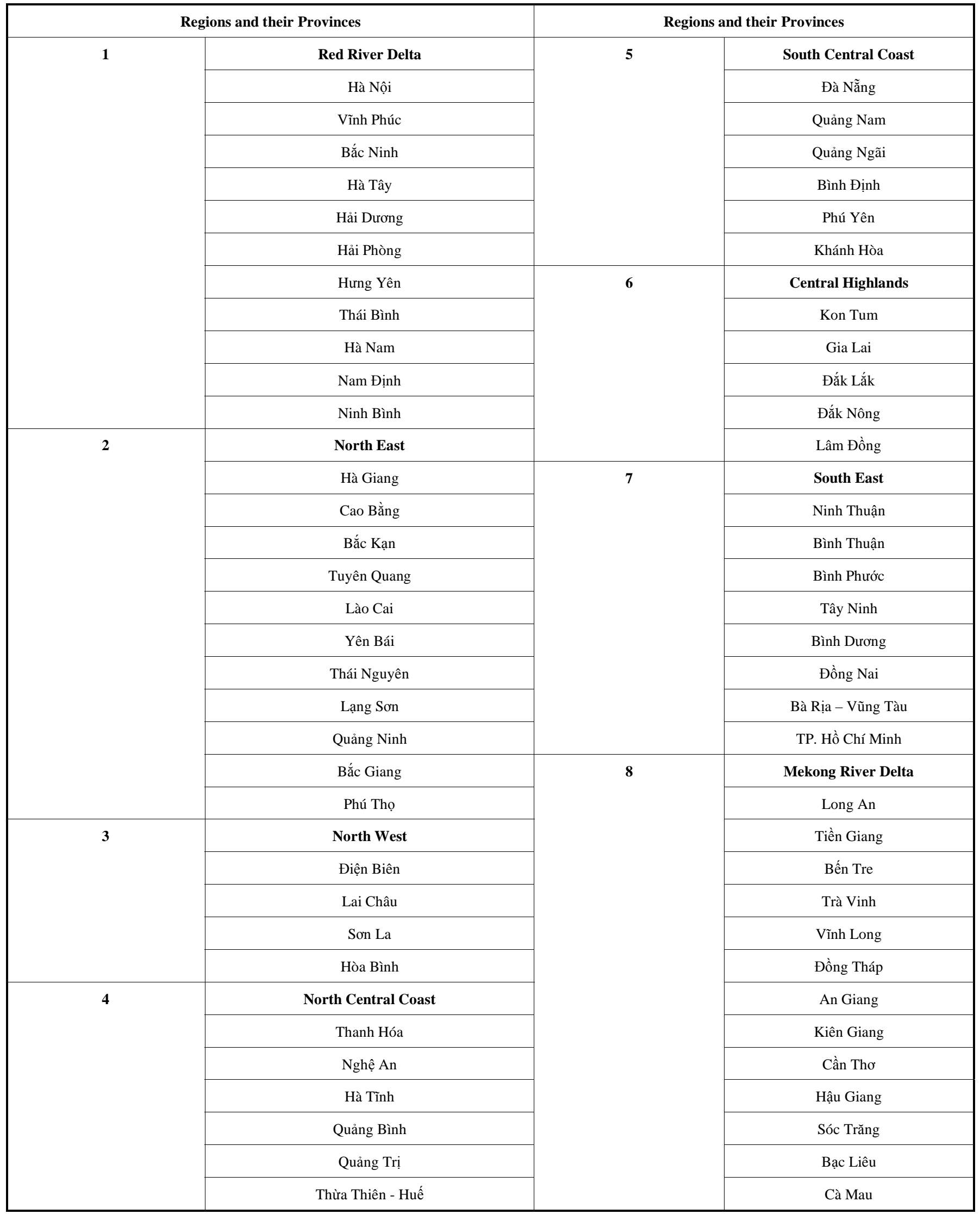




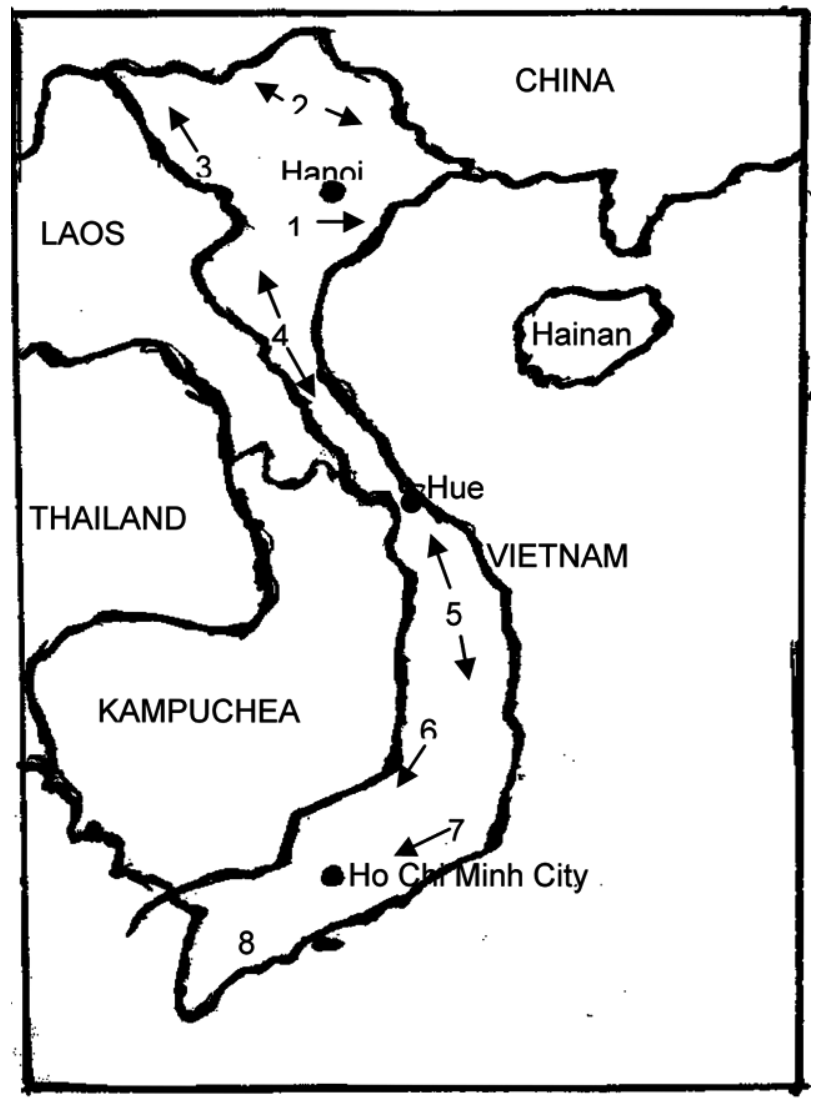

Fig. (9). A rough map of Vietnam. The numbers show approximate location of its statistical regions. They are as follows: (1) Red River Delta, (2) North East, (3) North West, (4) North Central Coast, (5) South Central Coast, (6) Central Highlands, (7) South East and (8) the Mekong River Delta.

Vietnam for 1996 and 2006. No major change occurred in the regional distribution of pig stocks. However, it can be seen that relative numbers declined on the North Central Coast, increased significantly in the South East and declined in the South Central Coast. In relation to the supply of pork, a noticeable feature is the relative decline in the importance of the South Central Coast and North Central Coast as sup- pliers of pork. Increases in the relative supply of pork from the South East Region and Red River Delta can be observed. Those regions that are well placed in relation to Hanoi and Ho Chi Min City continue to dominate as sources of pork supply in Vietnam.

\section{PORK YIELDS IN THE DIFFERENT REGIONS OF VIETNAM}

Between 1996 and 2006, pork yields increased in all regions of Vietnam, as can be seen from Fig. (12). Note that regional yields have been estimated by dividing annual volumes of pork supply for each region by pig numbers in each region, as reported by Vietnam's General Statistical Office.

The results indicate that considerable disparity continues to exist in pork yields between Vietnam's regions. For example, in 2006, the region with the highest yields (Mekong River Delta) had a yield of 3.41 times that of the region with the lowest yield (the North West Region). In 1996, this disparity was 3.34. Using this range as a measure, there appears to have been some increase in the disparity of pork yields between regions in Vietnam in 2006 compared to 1996 (see Appendix Table A3). Nevertheless, the calculations shown in the last column of Appendix Table A3 indicate that there has on average been some reduction in the relative deviation of regional yields away from the average national yield. This ratio fell from 0.29 in 1966 to 0.23 in 2006. Despite this, the average absolute deviation away from the average national yield rose from $18.27 \mathrm{kgs}$ to $21.83 \mathrm{kgs}$.

Disparity in the levels of pork productivity by regions in Vietnam may occur due to several factors. Differences could, for example reflect differences in the genetic composition of the pig stocks, and also could be a result of variations in nutrition and in husbandry techniques as well as climatic differences. However, variations in yield by regions cannot necessarily be said to demonstrate low economic efficiency in regions with low yields. Economic conditions can vary considerably by regions, and a high level of productivity (yield) in some areas may not be profitable.

Note that the three regions of Vietnam (the Mekong River Delta, the Red River Delta and the South West) had

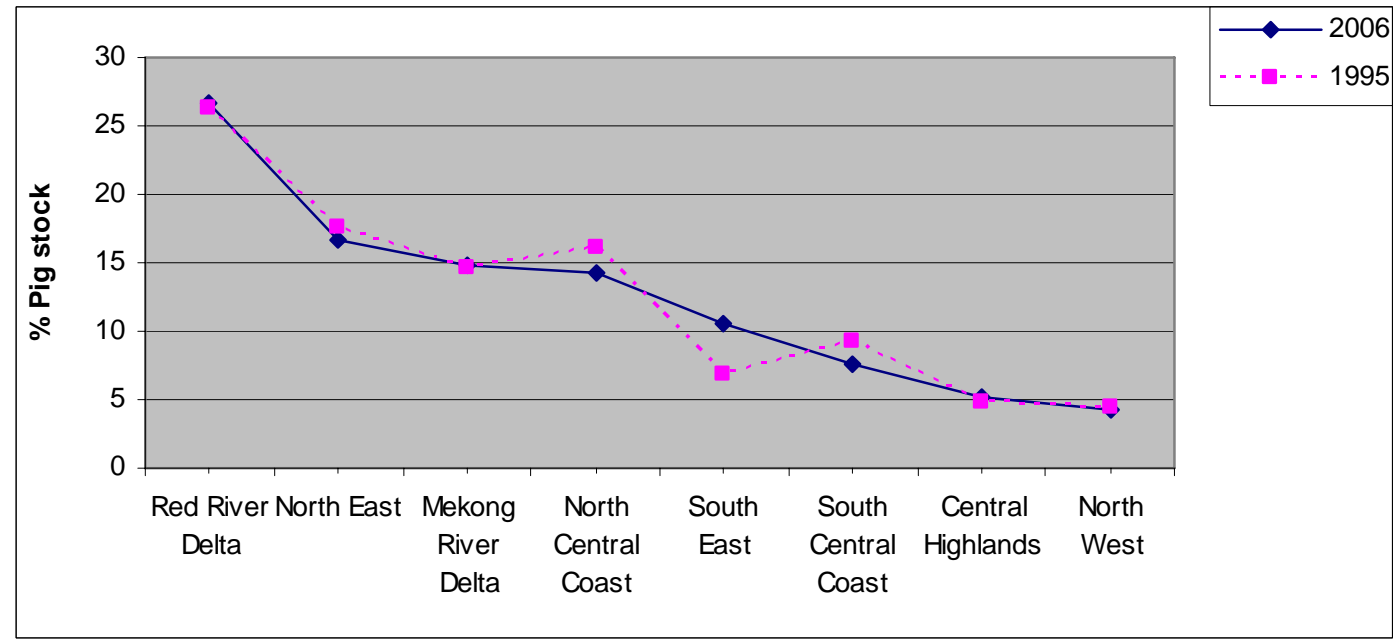

Fig. (10). Graph of the percentage of pig stocks accounted for by the different regions of Vietnam in 2006 and 1995 . In 1995 and 2006 the general regional distribution of pig stocks were similar, except that the percentage of pigs accounted for by the South East was higher in 2006 than 1996. (Source: based on Table A1). 


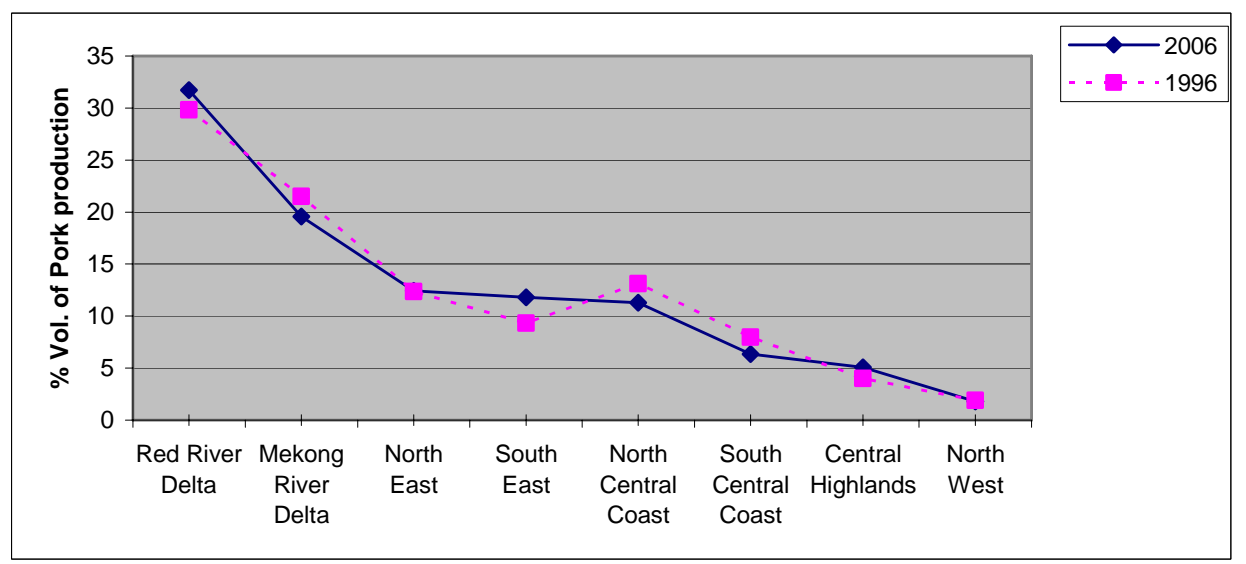

Fig. (11). Percentage of volume of pork production accounted for by the different regions of Vietnam in 2006 and 1996 . The relative contributions of the regions of Vietnam to its volume of pork production were similar in 1996 and 2006. However, the South East increased its relative contribution. (Source: based on Table A2).

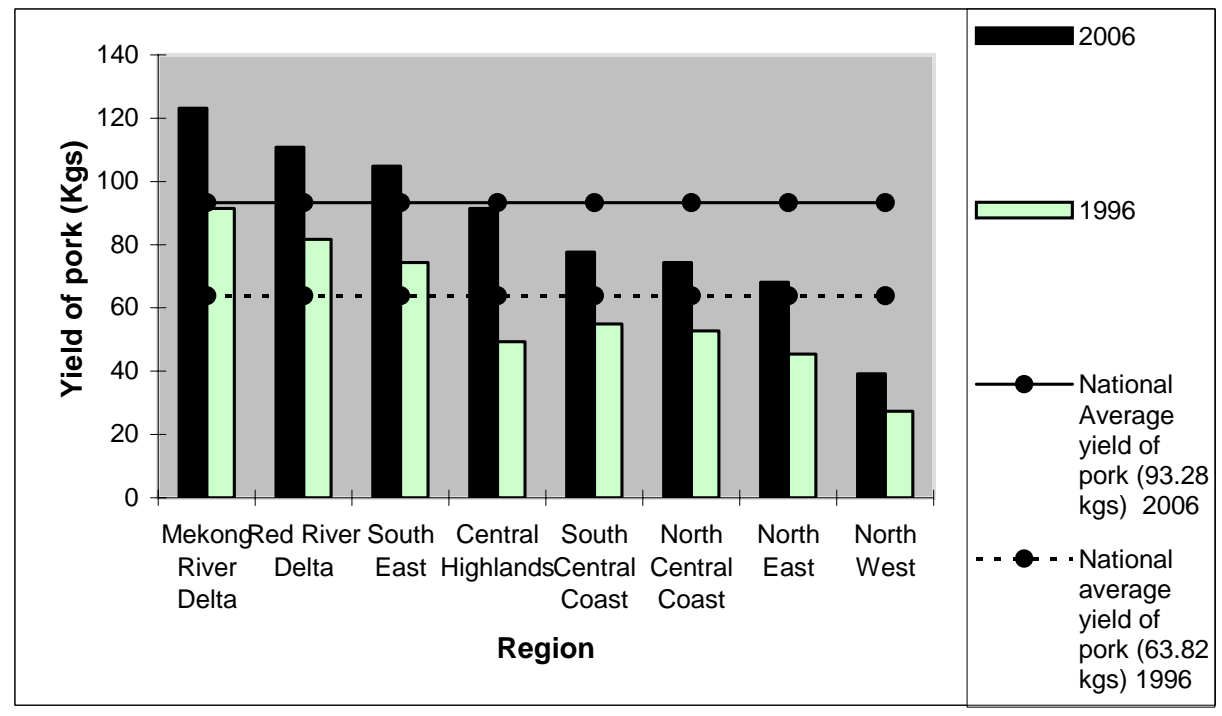

Fig. (12). Pork yields in the different regions of Vietnam in 1996 and 2006. Pork yields increased in all regions but remained very unequal. A number of measures indicate that the absolute inequality of regional yields has risen but there has been some reduction in their relative inequality. However, some regional inequality is likely to be economic. (Source: based on Table A3).

the highest levels of pork productivity (yields) in Vietnam in both 1996 and 2006 and the North West had the lowest yield in both years. Some changes in rankings occurred. For example, the Central Highlands moved from a ranking of $7^{\text {th }}$ place to $4^{\text {th }}$ place amongst the 8 regions and yields in this region rose from $49.37 \mathrm{kgs}$. to $91.47 \mathrm{kgs}$.

From Appendix Table A3, it appears that regions that surround or are close to Vietnam's major cities (namely Hanoi and Ho Chi Minh City) have the highest yield of pork in relation to pig stocks. This is probably because they have the most rapid adoption of new techniques for raising pork yields. They are more likely to switch to improved breeds and have less costly access to processed food on which these breeds thrive, have better living conditions for their pigs and easier access to and other support services.

It is also evident that pork yields in the North West region are much lower than in other regions in Vietnam. This is an area having many ethnic minorities and incomes are generally low in this region. Traditional agricultural methods and breeds of pigs are favoured in this region which lacks large human population centres.

There is considerable scope for future study of regional differences in pig yields in Vietnam and the reasons for these differences. The extent to which such differences are economic could also be studied, bearing in mind that high yields are unlikely to be economic in all regions of Vietnam. The actual socio-economic and environmental conditions in each region need to be taken into account in determining the type of husbandry of pigs and breeds of pigs that are likely to be most economic for local conditions. Vietnam has considerable regional diversity.

\section{DISCUSSION OF CURRENT POLICY ISSUES IN VIETNAM OF DIRECT RELEVANCE TO THE STRUCTURE OF THIS PIG SECTOR}

As observed above, the supply of pork in Vietnam is obtained to a large extent from many very small-scale household producers. Despite considerable increases in the pro- 
ductivity of Vietnam's pig sector since the mid-1990s, its cost of production of pork is still high in comparison to that in Canada and the USA. For example, a senior Vietnamese agricultural researcher stated at a meeting in Hanoi on 7 April, 2009 that the average cost of a kilogram of pork at the farm gate in the United States is USD 1.67 compared to USD 2.20 in Vietnam and Drucker et al. [1] provide evidence demonstrating the lack of international competitiveness of Vietnam's pork production. Vietnam's Government believes that the structure of its pig sector must be radically altered if the cost of its pork production is to be reduced [see for example, 6]. As part of its long-term plan for the development of its livestock industry up to 2020, the Government of Vietnam intends to adopt policy measures to increase the scale of production by its individual pig-producing units [11]. Its proposed new plan is similar to one adopted by China [12, p. 167]. The government believes that large-scale industrial production will reduce the cost of production of pork in Vietnam. Whether it will do so is analysed in Tisdell [13].

Some urgency is felt by Vietnam's Government in the need to reduce production costs in its pig sector because Vietnam is required to be compliant with the regulations of the WTO by 2012 and will need to reduce the extent of the economic protection of its pig industry. A subsidiary consideration is the Government's belief that larger pig-producing units will reduce the incidence of pig diseases, improve the hygiene of pig production and generally improve the quality of Vietnam's pork supply. It is not possible to assess these hypotheses here. However, it is worth noting that cultural (social habits) factors help to shield Vietnam's pig sector against imports. Vietnamese have a strong preference for fresh pork and have a relative dislike of chilled, frozen and processed pork which is mostly retailed in supermarkets.

The development of supermarkets in Vietnam has been slow [14, 15] and most Vietnamese prefer to buy (and do purchase) their pork fresh from traditional market-outlets, mainly permanent local markets [16, 17]. As long as this preference continues, the market opening in Vietnam for imported pork is relatively small because it is of necessity not fresh and its main retail outlet is through supermarkets. Although the characteristics of this market may alter in the longer term, it is unlikely to do so in the short-term. Change is likely to depend on further rises in income in Vietnam and alterations in the lifestyle of the Vietnamese. For the time being, the nature of demand for pork in Vietnam provides a degree of natural economic protection to its domestic pig sector [see 18]. That however, does not mean that efforts should not be made to reduce the cost of pork production in Vietnam, lower Vietnam's incidence of pig diseases and improve the quality of its pork.

\section{CONCLUDING OBSERVATIONS}

The volume of pork production, the number of pigs and the average yield of pork per pig in Vietnam's stock of pigs have risen greatly since 1996 . Vietnam's increased supply of pork since 1996 has been a result of increasing pig numbers and growing pork yields. While increased pig numbers accounted for the largest percentage of increased pork production between 1996 and 2006, increased yield was also important. In recent years, increased pork yield has become the major source of the growth in Vietnam's supply of pork. But the rate of growth in Vietnam's volume of pork supplies was not sustained in 2006. This could be an indication that the rate of growth in Vietnam's supply of pork is permanently slowing.

From the 2001 data, it was found that pig households account for over $90 \%$ of Vietnam's pig stocks. The average number of pigs held by households was quite small: 2.73 head. There has only been a slight increase in the average scale of pig-producing household unit since 2001. Registered pig farms account for less than $10 \%$ of Vietnam's pig stock and appear to vary significantly in size but usually operate on a larger scale than households. Registered pig farms are concentrated in the regions surrounding or near Hanoi and Ho Chi Minh City.

The number of pigs in the various regions of Vietnam differs considerably as does the volume of regional pork production. The Red River Delta, the Mekong River Delta, the North East and the South East were the most important sources of pork supply in 2006. Some regional changes in the regional supply of pork occurred between 1996 and 2006 but no major change is apparent. Regional variations in pork yields are considerable. Yields are highest in regions containing Vietnam's two major cities or close by, and reasons for this were given. Although all regions of Vietnam have recorded increased pork yields since 1996, there has been no reduction in the disparity of the regional yields.

It is apparent that intensification of Vietnam's pig sector has increased since 1996 and that pork production has become more market dependent. Therefore, the economic future of Vietnam's pig sector depends more than ever on changing market conditions. This means that the economic vulnerability of Vietnam's pig sector to external and (noncontrolled) market forces has increased.

Despite positive indicators of its improved economic performance in the period 1996-2006, Vietnam's pig industry has yet to achieve a strong competitive position internationally [1]. This is reflected in its meagre level of exports of pork and since 2006, its rising imports of chilled and frozen pork from North America. These developments are likely to accelerate structural change in Vietnam's pork industry which so far has been slow to alter its structure. Unfortunately, increased pork yields and better quality pork produced in Vietnam are not certain to prevent further penetration of Vietnam's pork market by imports. However, the fact that Vietnamese have a strong preference for fresh pork and a relative dislike of chilled frozen and processed pork provides some natural economic protection to Vietnam's pig sector. The slow development of supermarkets in Vietnam combined with the preference of Vietnamese for buying pork from traditional retail outlets further reinforces this natural protection of the local industry from imports of pork.

\section{ACKNOWLEDGEMENTS}

This article is an output from a research project entitled "Improving the competitiveness of pig producers in an adjusting Vietnam market" supported by the Australian Centre for International Agricultural Research (ACIAR) and the International Livestock Institute (ILRI) and conducted in cooperation with the Center for Agricultural Policy (CAP) of 
Vietnam. I wish to thank Ma. Lucy Lapar of ILRI and Pham Phuong of International Center for Agricultural Policy, Vietnam, for assisting with the supply of official statistics, and Zeeshan Rahman for her research assistance as well as Evelyn Smart for her help with the processing of this article for publication. The original paper was presented at a work- shop held in Hanoi on August 22, 2008 and was subsequently revised and updated. It has benefited from comments received on this occasion as well as from suggestions of two anonymous referees for TOARSJ. All statistics used in this paper are from sources of the General Statistical Office, Hanoi. The usual caveat applies.

\section{APPENDIX}

Table A1. Percentage of Pig Stocks Accounted for to the Different Regions of Vietnam in 2006 and 1995 . There is Considerable Regional Inequality in the Number of Pigs in Vietnam in Both Years. (Source: Based on [5] Table 4)

\begin{tabular}{|c|c|c|}
\hline \multicolumn{3}{|c|}{ YEAR : 2006 } \\
\hline Rank & Region & \% Pig Stock \\
\hline \hline 1 & Red River Delta & 26.69 \\
\hline 2 & North East & 16.75 \\
\hline 3 & Mekong River Delta & 14.83 \\
\hline 4 & North Central Coast & 14.17 \\
\hline 5 & South East & 10.50 \\
\hline 6 & South Central Coast & 7.64 \\
\hline 7 & Central Highlands & 5.16 \\
\hline 8 & North West & 4.26 \\
\hline
\end{tabular}

\begin{tabular}{|c|c|c|}
\hline \multicolumn{3}{|c|}{ YEAR : 1995 } \\
\hline Rank & Region & \% Pig Stock \\
\hline \hline 1 & Red River Delta & 26.24 \\
\hline 2 & North East & 17.59 \\
\hline 4 & Mekong River Delta & 14.58 \\
\hline 3 & North Central Coast & 16.17 \\
\hline 6 & South East & 6.94 \\
\hline 5 & South Central Coast & 9.21 \\
\hline 7 & Central Highlands & 4.80 \\
\hline 8 & North West & 4.47 \\
\hline
\end{tabular}

Table A2. Percentage of Volume of Pork Production Accounted for by the Different Regions of Vietnam in 2006 and 1996 . There is Considerable Inequality in the Regional Supply of Pork in Both Years

\begin{tabular}{|c|c|c|}
\hline \multicolumn{3}{|c|}{ YEAR: 2006 } \\
\hline Rank & Region & \%Pork Production \\
\hline \hline 1 & Red River Delta & 31.72 \\
\hline 2 & Mekong River Delta & 19.57 \\
\hline 3 & North East & 12.42 \\
\hline 4 & South East & 11.79 \\
\hline 5 & North Central Coast & 11.29 \\
\hline 6 & South Central Coast & 6.36 \\
\hline 7 & Central Highlands & 5.06 \\
\hline 8 & North West & 1.79 \\
\hline
\end{tabular}

\begin{tabular}{|c|c|c|}
\hline \multicolumn{3}{|c|}{ YEAR: 1996 } \\
\hline Rank & Region & \%Pork Production \\
\hline \hline 1 & Red River Delta & 29.83 \\
\hline 2 & Mekong River Delta & 21.52 \\
\hline 4 & North East & 12.35 \\
\hline 5 & South East & 9.33 \\
\hline 3 & North Central Coast & 13.12 \\
\hline 6 & South Central Coast & 7.96 \\
\hline 7 & Central Highlands & 3.99 \\
\hline 8 & North West & 1.89 \\
\hline
\end{tabular}

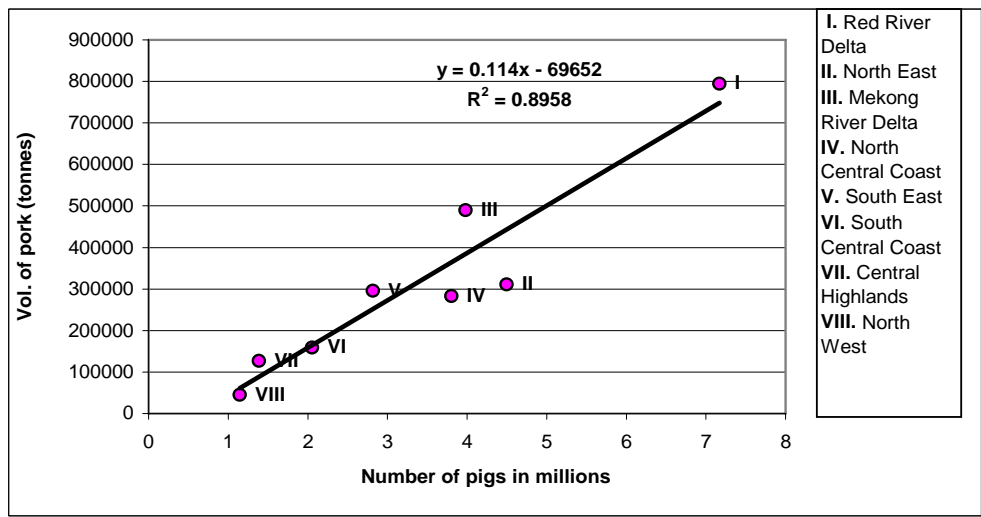

Fig. (A1). Volume of pork in relation to pig stocks in the different regions of Vietnam in 2006. There is a relatively close association between volume of pork produced in each of the regions and the stock of pigs in each. Note that $\mathrm{x}$ in the equation refers to the number of pigs. (Source: based on [5], Tables A1 and A2) 
Table A3. Yields of Pork in Relation to Pig Stocks in the Different Regions of Vietnam in 2006 and 1996. (Based on [5], Tables A4 and A5). The Absolute Regional Disparity of Yields has Increased but the Relative Disparity is Virtually Unchanged

\begin{tabular}{|c|c|c|c|c|c|}
\hline \multicolumn{7}{|c|}{ YEAR : 2006 } \\
\hline Region & Rank & $\begin{array}{c}\text { Pig Yield } \\
(\text { Kgs })\end{array}$ & Rank & $\begin{array}{c}\text { Pig Stock } \\
\text { (Numbers) }\end{array}$ & $\begin{array}{c}\text { Deviation of Regional from } \\
\text { National Avg. Yield of 93.28 kgs. }\end{array}$ \\
\hline \hline Mekong River Delta & 1 & 123.11 & 3 & $3,982,000$ & 29.83 \\
\hline Red River Delta & 2 & 110.83 & 1 & $7,168,800$ & 17.55 \\
\hline South East & 3 & 104.81 & 5 & $2,819,000$ & 11.53 \\
\hline Central Highlands & 4 & 91.47 & 7 & $1,386,200$ & -1.81 \\
\hline South Central Coast & 5 & 77.59 & 6 & $2,052,000$ & -15.69 \\
\hline North Central Coast & 6 & 74.36 & 4 & $3,804,600$ & -18.92 \\
\hline North East & 7 & 68.10 & 2 & $4,498,300$ & -25.18 \\
\hline North West & 8 & 39.18 & 8 & $1,144,400$ & -54.10 \\
\hline
\end{tabular}

Average absolute deviation in yield $=21.83$.

divided by national average $=0.23$.

\begin{tabular}{|c|c|c|c|c|c|}
\hline \multicolumn{7}{|c|}{ YEAR : 1996 } \\
\hline Region & Rank & $\begin{array}{c}\text { Pig Yield } \\
\text { (Kgs) }\end{array}$ & Rank & $\begin{array}{c}\text { Pig Stock } \\
\text { (Numbers) }\end{array}$ & $\begin{array}{c}\text { Deviation of Regional from } \\
\text { National Avg. Yield of 63.82 kgs }\end{array}$ \\
\hline \hline Mekong River Delta & 1 & 91.42 & 4 & $2,542,100$ & 27.60 \\
\hline South East & 2 & 81.62 & 6 & $1,235,000$ & 17.80 \\
\hline Red River Delta & 3 & 74.30 & 1 & $4,336,200$ & 10.48 \\
\hline South Central Coast & 4 & 54.95 & 5 & $1,565,200$ & -8.87 \\
\hline North Central Coast & 5 & 52.77 & 3 & $2,685,300$ & -11.05 \\
\hline Central Highlands & 6 & 49.37 & 7 & 873,000 & -14.45 \\
\hline North East & 7 & 45.39 & 2 & $2,939,100$ & -18.43 \\
\hline North West & 8 & 27.35 & 8 & 745,800 & -36.47 \\
\hline
\end{tabular}

Average absolute deviation in yield $=18.27$.

divided by national average $=0.29$.

\section{REFERENCES}

[1] Drucker AG, Bergeron E, Lemke U, Thuy LT, Zarate AV. Identification and quantification of subsidies relevant to the production of local and imported pig breeds in Vietnam. Trop Anim Health Prod 2006; 38: 305-22.

[2] Tisdell CA, Wilson C. Breeding and feeding pigs in Vietnam. Canberra: Australian Centre for International Agricultural Research 2001.

[3] Tisdell CA, Wilson C. Genetic selection of livestock and economic development. In: Tisdell $\mathrm{C}$, Ed. Economics and ecology in agriculture and marine production. Cheltenham, UK and Northampton, MA, USA: Edward Elgar 2003.

[4] Nguyen AP, Nguyen QN, Pham LP. Current meat consumption patterns of Vietnam. ACIAR Midterm Project Review Workshop for the project "Improving the Competitiveness of Pig Producers in an Adjusting Vietnam Market"; 7 April Fortuna Hotel, Hanoi 2009.

[5] Tisdell CA. Structural transformation in the pig sector in an adjusting Vietnam market: a preliminary investigation of supplyside changes. Brisbane, Australia: The University of Queensland 2008.
[6] Landell Mills Ltd. Preparation study for livestock competitiveness and food safety project. Vietnam and for the World Bank: Ministry of Agriculture and Rural Development 2007.

[7] Conway GR. The properties of agroecosystems. 1987; 24: 95-117.

[8] Tisdell CA. Economics and ecology in agriculture and marine production. Cheltenham, UK and Northampton, MA, USA: Edward Elgar 2003.

[9] General Statistical Office of Vietnam. Results of the 2001 Rural, Agricultural and Fisheries Census. Hanoi: Statisical Publishing House 2002.

[10] General Statistical Office of Vietnam. Results of the 2006 Rural, Agricultural and Fisheries Census. Hanoi: Statistical Publishing House 2007.

[11] Ministry of Agriculture and Rural Development Vietnam. Animal husbandry strategies (2020). Hanoi: MARD 2007.

[12] Ministry of Agriculture of China. China animal husbandry industry handbook 1999. Beijing: China Agricultural Press 2000.

[13] Tisdell CA. The survival of small-scale agricultural producers in Asia, particularly Vietnam: general issues illustrated by Vietnam's agricultural sector, especially its pig production. Sustainable agriculture: Technology, planning and management. New York: Nova Science Publishers 2009 in Press. 
[14] Chen K, Shepherd A, da Silva C. Changes in food retailing in Asia: implications of supermarket procurement practices for persons and traditional marketing systems. Agricultural Management, Marketing and Finance. Rome: FAO 2005.

[15] Maruyama M, Trung LV. Supermarkets in Vietnam: Opportunities and obstacles. Asian Econ J 2007; 23: 19-46.

[16] Nguyen TH, Wade J. US meat and dairy products help meet Vietnam's demand. Washington, D.C.: United States Department of Agriculture 2006.

[17] Lapar MLA, Toan NN, Que NN, Jabbar M, Tisdell CA, Staal S. Market outlet choices in the context of changing demand for fresh meat: Implications for smallholder inclusion in pork supply chain in Vietnam. A contributed paper to the 27th Conference of the International Association of Agricultural Economists; Beijing August 16-22, 2009.

[18] Tisdell CA, Lapar MLA, Staal S, Que NN. Natural protection from competition in the livestock industry: analysis, examples and Vietnam's pork market as a case. Agricultural economics: New research. New York: Nova Science 2009 forthcoming.

(C) Clem Tisdell; Licensee Bentham Open.

This is an open access article licensed under the terms of the Creative Commons Attribution Non-Commercial License (http://creativecommons.org/licenses/ by-nc/3.0/) which permits unrestricted, non-commercial use, distribution and reproduction in any medium, provided the work is properly cited. 